\title{
Histological Study of Thyroid Gland after Experimental Exposure to Low Frequency Electromagnetic Fields in Adult Male Albino Rat and Possible Protective Role of Vitamin E
}

\section{Dalia A Mohamed and Heba M Elnegris*}

Department of Histology and Cell Biology, Faculty of Medicine, Zagazig University, Egypt

\begin{abstract}
Introduction: Thyroid gland is one of the most important endocrine organs and almost all cells of the body are target sites for its hormones. Electromagnetic field became progressively more common constituent of the general and workplace environments.

Aim of work: To evaluate the effect of low frequency electromagnetic fields (LF-EMF) on the structure and function of the thyroid gland and to evaluate their reversibility and role of vitamin $\mathrm{E}$.

Materials and Methods: Forty five adult male albino rats were equally divided into four groups; group I (control group), group II: rats were exposed to $50 \mathrm{~Hz}$ EMF for 1 month, group III: rats were received vitamin E just before EMF exposure for the same period and group IV (recovery group). At the time of sacrifice, blood samples were collected to estimate TSH, T3 and T4 levels. Thyroid gland specimens were processed for microscopic examination. The heights of follicular epithelium, collagen fiber area \% were morphometrically estimated and statistically analyzed.

Results: Exposed group showed significant decline T3 and T4 levels together with significant increase in TSH level as compared to other groups. Histologically, this group showed congestion and dilatation of blood capillaries, cellular infiltration, follicular disintegration and vacuolar degeneration of some follicular cells. Other apoptotic follicular cells appeared with condensed chromatin or desquamated. The epithelial height and connective tissue area also affected. Vitamin E improves the biochemical and histological picture of thyroid gland (group III). Recovery group (IV) had variable alteration as compared to other groups.
\end{abstract}

Conclusion: LF-EMF has very serious effect on thyroid gland and vitamin $E$ could have a protective role against this tissue damage.

Keywords: EMF; Thyroid gland; Ultrastructure; Vitamin E

\section{Introduction}

During the last decades of the $20^{\text {th }}$ century, the constant enhancement of electrical power use led to increased exposure of living organisms, especially the human population, to a variety of artificially produced electromagnetic fields (EMFs). These fields originate from a number of different sources and are characterized by various frequencies and intensities [1].

Electric and magnetic fields are present around electrical equipment and wiring all through industry. The EMFs can be classified into static, extremely low frequency, intermediate frequency and radiofrequency fields. Among the previous types; the low frequency (LF) electromagnetic field (EMF) is wide spread in human environment and has a considerable attention among scientific community. This field can originate from sources as trains for public transport, any device involved in the generation, distribution or use of electric power [1]. Also, it can be produced by power lines and many kinds of electric appliances [2-4].

For many years, ELF-EMFs were considered as an absolutely neutral form of radiation [5]. Epidemiological data and results of many experimental studies have suggested that their consequences on human health become the subject of immense public debate [6] and one of the major concerns [7]. There have been many studies of the possible relations between residential exposure to ELF-EMFs and some kinds of cancer, including leukemia, lymphomas, brain, lung and breast tumors [8].

International Agency for Research on Cancer has evaluated the ELF-EMF as possibly carcinogenic to humans (Group 2B) [9].
Among the characteristic biological effects of EMF are the functional changes in CNS, endocrine and immune systems [Ahlbom 2001 Additionally, EMF can influence the learning and memory, cardiovascular system and reproductive system $[10,11]$.

Concerning the endocrine system; the sensitivity of pineal, pituitary, adrenal and thyroid glands as well as of the islet of pancreas, testicles and ovaries to EMFs has been reported [12].

Thyroid gland is considered as body's primary regulator of metabolism through the action of thyroid hormones (T3 and T4). High concentration of these hormones may change the metabolism of oxygen in many cells and stimulate the production of free radicals in them [13].

The thyroid is considered as one of the most exposed vital organs and may be a target for EM radiation [12]. However, only few papers report the biological effect of low frequency EMF on the function and histological structure of thyroid gland. So, objective of the present study

*Corresponding author: Heba Mohamed Elnegris, Department of Histology and Cell Biology, Faculty of Medicine, Zagazig University, Egypt, Tel: 01011061300; E-mail: heba31076@yahoo.com

Received July 23, 2015; Accepted September 29, 2015; Published October 02, 2015

Citation: Mohamed DA, Elnegris HM (2015) Histological Study of Thyroid Gland after Experimental Exposure to Low Frequency Electromagnetic Fields in Adult Male Albino Rat and Possible Protective Role of Vitamin E. J Cytol Histol 6: 374 doi:10.4172/2157-7099.1000374

Copyright: @ 2015 Mohamed DA, et al. This is an open-access article distributed under the terms of the Creative Commons Attribution License, which permits unrestricted use, distribution, and reproduction in any medium, provided the original author and source are credited. 
was to study the EMF-induced alterations in the histological structure and function of thyroid gland. It was also aimed to evaluate the reversibility of such changes with or without vitamin E supplementation.

\section{Materials and Methods}

\section{Study protocol}

Forty five healthy adult ( 2 month-old) male albino rats weighing 180-200 gram were used in this study. The rats were obtained from the Laboratory Animals Unit, Faculty of Veterinary Medicine, Zagazig University, Egypt. They were housed in plastic cages to avoid any metallic interaction under environmental laboratory condition at $20 \pm$ $2^{\circ} \mathrm{C}$. The animals were subjected to a controlled photoperiod ( $14 \mathrm{~h}: 10$ $\mathrm{h}$ light:dark), were allowed water ad-libitum and fed standard diet. The experiment was performed in accordance with the "Guide for the Care and Use of Laboratory Animals" [14]. The experimental protocol was approved by the Ethical Committee of Zagazig University.

After an acclimatization period of 1 week, rats were randomly divided into four equal groups; I, II, III and IV

Group I (control group): was subdivided equally into two subgroups (five each):

Subgroup Ia : Rats were maintained in an environment without the presence of artificially produced EMF.

Subgroup Ib: Rats stayed in the experimental setup with the same conditions as the exposure group but without radiation exposure (exposure device off) and considered as sham-exposed group.

Subgroup Ic: Rats were given corn oils orally by modified gastric syringe ( $5 \mathrm{ml} / \mathrm{kg}$ /day).

Group II (EMF-exposed): included ten rats that were exposed individually to the influence of electric magnetic field 4 hours/day for 1 month [15].

Group III (EMF-exposed-vitamin E): included ten rats that were exposed to EMF as group II and received vitamin E $150 \mathrm{mg} / \mathrm{kg} /$ day by IM injection just before EMF exposure all over the experimental period (1 month).

Group IV (recovery group): included ten rats that were kept alive for another 1 month after exposure without treatment.

At the time of sacrifice, rats were anesthetized with intraperitoneal injection of sodium pentobarbital (Nembutal, $30 \mathrm{mg} / \mathrm{kg}$ body weight). The blood samples were collected through a cardiac puncture [6] from all groups for hormonal assay. After opening the thorax, all animals were perfused with phosphate buffered saline (PBS) followed by a fixative containing $4 \%$ paraformaldehyde, $5 \%$ glutaraldehyde in 0.1 $\mathrm{M}$ cacodylate buffer, $\mathrm{pH} 7.4$ for 5-8 minutes [16]. Then the thyroid gland of each rat was excised and was processed for light and electron microscope examinations.

Specimens for light microscopic examination; were fixed in $10 \%$ neutral formol saline for 24 hours and were processed to prepare $5 \mu \mathrm{m}$ thick paraffin sections for Haematoxylin and Eosin (H\&E) to verify the histological details and Mallory's trichrome stain to demonstrate the collagen fiber in the tissue [17].

Specimens for electron microscope; were immediately fixed in phosphate buffered glutaraldehyde ( $\mathrm{pH}$ 7.4). Then post fixed in osmium tetroxide in the same buffer at $4^{\circ} \mathrm{C}$, dehydrated and embedded in epoxy resin. Semi-thin sections $(1 \mu \mathrm{m}$ thick) were stained with toluidine blue for light microscope examination [18]. Ultra-thin sections were stained with uranyl acetate and lead citrate [18] and were examined and photographed with JEOL JEM 1010 electron microscope in Electron Microscope Research Laboratory (EMRL) of Histology and Cell Biology Department, Faculty of Medicine, Zagazig University.

\section{Experimental setup and exposure system (magnetic field generator system)}

Magnetic field (MF) was produced by homogenous magnetic field generator, which designed in Physics Department, Faculty of Science, Cairo University, Egypt. The system formed of a solenoid consisting of 320 turns from electrically insulated $2 \mathrm{~mm}$ cupper wire thickness wound in a homogenous way around a cupper cylinder $1.5 \mathrm{~mm}$ thick, $40 \mathrm{~cm}$ diameter and $25 \mathrm{~cm}$ length. The cylinder wall earthed to eliminate electric field components effects. The magnetic field generator was temperature controlled during the exposure period by using a water pump. The cage of the rats was put in the middle of the coil by using supports inside it to get a homogenous and higher magnetic fields strength. The ends of coil are connected to variac fed from the mains $(220 \mathrm{v}, 50 \mathrm{~Hz})$. The field strength was $20 \mathrm{G}$ (gauss) and adjusted by changing the voltage through the coil.

\section{Morphometrical study}

Serial sections stained with H\&E and Mallory's trichrome sections were morphometrically analyzed for detection of epithelial height and area \% of collagen fibers in the septa, around the duct and the blood vessels using Leica Qwin 500 image analyzer computer system (Cambridge, England) in the image analyzing unit of the Pathology Department, Faculty of Dentist, Cairo University, Egypt. The measuring frame of a standard area is equal to $7286,78 \mu \mathrm{m}^{2}$. For each parameter ten different non overlapping fields from ten different specimens were examined in each group.

\section{Hormonal assay}

The blood samples were collected into the glass tubes (without anticoagulant) to clot. It was centrifuged to obtain serum and then stored at $-20^{\circ} \mathrm{C}$ until the assay. TSH, Total T3 and T4 hormone levels were measured using RIA Kit (Diagnostic Products Corporation, LA, USA).

\section{Statistical analysis}

Data for all groups were expressed as mean \pm standard deviation (mean $\pm \mathrm{SD}$ ). The data obtained from the image analyzer and the biochemical data were subjected to SPSS program version 15 . Statistical analysis using one way analysis of variance (ANOVA) test is used for comparison between different groups. The results were considered statistically significant when the probability $(\mathrm{P})$ value $<0.05$.

\section{Results}

\section{Histological results}

Group I (control group): Histological examination of all control subgroups; Ia, Ib and Ic showed nearly similar structure. Figures for subgroup Ia were used to differentiate with other groups. The thyroid gland of control animals showed well formed, closely impacted follicles separated by thin connective tissue septa. The thyroid follicles had variable sizes and shapes. Their lumina contained homogenous acidophilic structure less colloid. Groups of interfollicular cells were observed. The central follicles were lined by single layer of cuboidal cells with rounded nuclei while the peripheral follicles were lined 
Citation: Mohamed DA, Elnegris HM (2015) Histological Study of Thyroid Gland after Experimental Exposure to Low Frequency Electromagnetic Fields in Adult Male Albino Rat and Possible Protective Role of Vitamin E. J Cytol Histol 6: 374. doi:10.4172/2157-7099.1000374

by flattened or low cuboidal cells. The colloid showed conspicuous peripheral vacuoles (Figure 1A). Little amount of collagen fiber was seen in connective tissue septa (Figure 1B). Additionally, parafollicular cells (C-cells) were observed in some follicles resting on the basement membrane and had large pale nuclei. Vascular connective tissue septa were seen between the follicles (Figure 2A).

Group II (EMF exposed group): The gland in the exposed group showed disintegration and disorganization of thyroid follicles. Some follicles appeared with interrupted follicular wall. Congested blood vessels were seen in C.T septa (Figure 1C). Many collagen fibers were detected in the connective tissue septa (Figure 1D). Additionally, some follicular cells had darkly stained nuclei and interfollicular cellular infilteration. Desquamated epithelial follicular cells in the lumen (Figures 2B and 2C) are also seen.
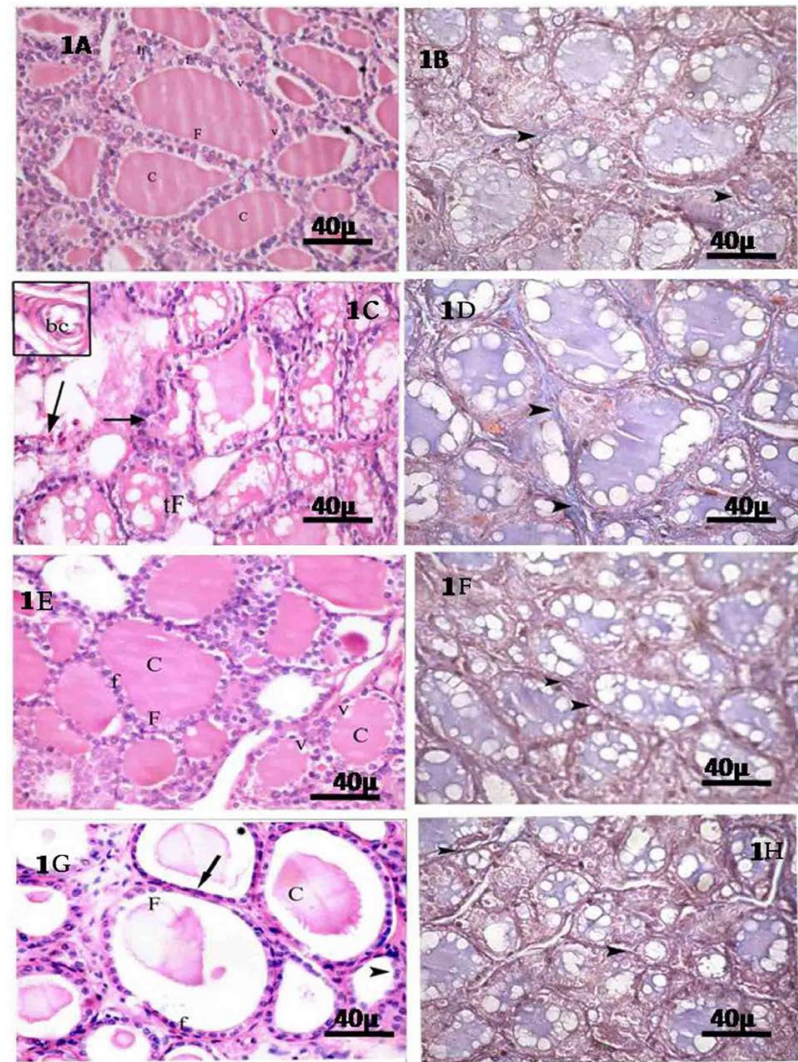

Figure 1: control group (I); 1A, B: 1A: H\&E stained section showing variable sized follicles. Central follicles $(F)$ are lined by single layer of cuboidal cells with rounded nuclei (f) while the peripheral follicles have flattened or low cuboidal cells $\left.{ }^{*}\right)$. Their lumina are filled with homogenous acidophilic structurless colloid (C) .It shows conspicuous peripheral vacuoles (v). Group of interfollicular cells are also observed (If). 1B mallory's trichrom stained section showing little collagen fibers (arrow head) in the connective tissue septa. EMF-exposed group (II) 1C, D: 1C: H\&E stained sections showing disintegration and disorganisation of thyroid follicles with interrupted follicular wall (tF). Inset: congested blood vessels (bc) in C.T septa. 1D: mallory's trichrome stain section showing many collagen fibers (arrow head) in connective tissue septa. vitamin E-treated group(III) 1E,F: 1E: H\&E stained sections reveal many recovered thyroid follicles $(F)$. These follicles are lined by cuboidal cells (f) with rounded nuclei. Note, return of peripheral vacuolation $(v)$ in the colloid(C).1F: mallory's trichrome stained sections showing minimal collagen fibers (arrow head) in the connective tissue between the follicles. Recovery group (IV) 1G,H: 1G: $\mathrm{H} \& \mathrm{E}$ stained sections showing apparently normal variable sizes follicles (F). Some follicles appear distended $\left(^{*}\right)$ with colloid $(\mathrm{C})$ and lined by flat cells (arrow). Other follicles have cuboidal cells (f) with rounded nuclei. Notice, there are involuted follicle (arrow head). 1H: mallory's trichrome stained sections showing moderate amount of collagen fibers (arrow head) in connective tissue septa between the follicles. (scale bar=40 $\mu \mathrm{m}$ )

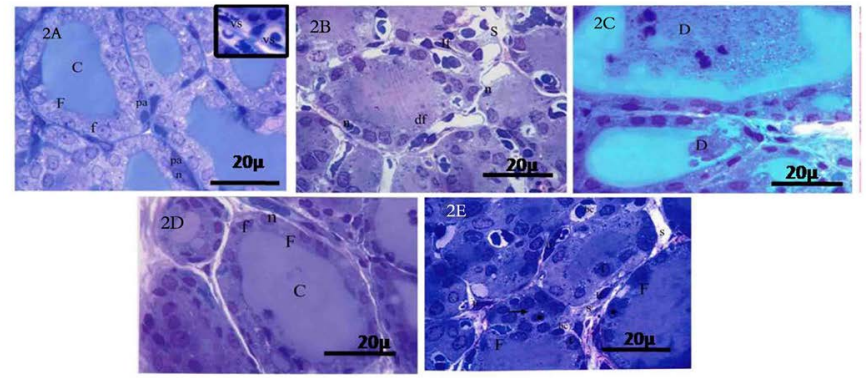

Figure 2: Control group (I) 2A: Toluidine blue stained section reveal follicles (F) lined by cuboidal cells with rounded nuclei (f). These follicles are filled with colloid $(C)$. Parafollicular $C$ cell (pa) resting on the basement membrane have large pale nuclei (n).Inset: note the vascular connective tissue septa (vs) between the follicles. EMF-exposed group (II) 2B: Toluidine blue stained section showing disorganized thyroid follicles (df) with wide interfollicular spaces (S) Some follicular cells have dakely stained nuclei $(n)$. Note, interfollicular cellular infilteration (If). 2C: demonstrate desquamated epithelial follicular cell (D). Vitamin E-treated group (III) 2D: Toluidine blue stained section reveal nearly normal thyroid follicles $(F)$. They are filled with homogenous colloid $(C)$ and lined by cuboidal cells (f) with vesicular rounded nuclei (n). Recovery group (IV) 2E: Toluidine blue stained section reveal variable shaped thyroid follicles (F) Some of them are involuted (arrow). Some follicles have darkely stained nuclei $\left({ }^{*}\right)$, others have normal cuboidal cells (f). Notice, wide intefollicular spaces (S) containing many blood vessels (bc) and cellular infilteration (If) (scale bar=20 $\mu \mathrm{m})$

Group III (EMF exposed- vitamin E treated group): Some thyroid follicles in group III that treated with vitamin E during EMF exposure retained the appearance of controlled follicles. They were lined by cuboidal cells that had rounded nuclei. Some follicles were distended with colloid that showed peripheral vacuolation (Figure 1E). Minimal collagen fibers were seen in interfollicular connective tissue septa (Figure 1F). Semithin sections of the same group revealed nearly normal thyroid follicles that lined by cuboidal cells with rounded vesicular nuclei as well s distended with homogenous colloid (Figure 2D).

Group IV (recovery group): The thyroid gland of recovery group showed preserved secretory activity. It was mainly characterized by nearly normal thyroid follicles that lined with flattened or low cuboidal epithelium. There are some involuted follicles (Figure 1G). Moderate amount of collagen fibers could be seen in the interfollicular spaces (Figure 1H). Semithin sections of this group showed variable shaped thyroid follicles, some of them were involuted. Few follicles had darkly stained nuclei, others had normal cuboidal cells. Wide intefollicular spaces contained many blood vessels and cellular infilteration (Figure 2E).

\section{Electron microscopic results}

Ultrstructurally, the the normal histological structure of thyroid gland were found in all subgroups of control rats. Thyroid gland of this group showed rounded follicles that formed of cuboidal cells. The follicles were bounded with thin basement membranes that surrounded with capillaries. The follicular cells had euchromatic rounded nuclei with clumps of heterochromatin also their apical surfaces showed microvilli (Figure 3A). Their cytoplasm contained rough endoplasmic reticulum with dilated citsternae, intracytoplasmic vacuoles. The apex of the cells, adjacent to the follicular lumen, showed apical cytoplasmic vacuolization with the presence of many lysosomes (Figure 3B). While parafollicular (C)cells appeared with rounded euchromatic nuclei, homogenous cytoplasm containing mitochondria, few tubular cisternae of rough endoplasmic reticulum (RER) and fine electron dense granules (Figure 3C).

Group II (EMF exposed group): In rats exposed to EMF, Some 
Citation: Mohamed DA, Elnegris HM (2015) Histological Study of Thyroid Gland after Experimental Exposure to Low Frequency Electromagnetic Fields in Adult Male Albino Rat and Possible Protective Role of Vitamin E. J Cytol Histol 6: 374. doi:10.4172/2157-7099.1000374

of the follicles were lined by high cuboidal cells with rounded nuclei and clumps of peripheral heterochromatin. Their cytoplasm contained several vacuoles, electron dense lysosomes. Dilated cisternae of RER lost their lamellar arrangement were also observed. Their apical border $\mathrm{s}$ showed microvilli. In some cells, nuclei appeared often irregular in shape, shrunken with condensed heterochromatin (Figures 3D and 3E). The interstitium contained dilated congested blood capillaries, large amount of collagen fibers, fibroblast (Figure $3 \mathrm{~F}$ ) and different cells are also seen (Figure 4A). Parafollicular cells had oval nuclei. Their cytoplasm contained abnormal mitochondria with ruptured cristea and few granules (Figure 4B).

Group III (EMF exposed- vitamin E treated group): In vitamin E-treated group, the thyroid follicles were lined by cuboidal cells with ovoid euchromatic nuclei. Their cytoplasm contained dilated cisternae of RER and lysosomes and few colloid vacuoles. Notice microvilli at apex of follicular cells (Figure 4C). Parafollicular cell with indented nucleusand peripheral condensation of heterochromatin, few electron dense granules and lysosomes were demonstrated (Figure 4D).

Group IV (recovery group): Electron microscopic examination of thyroid follicles in recovery rats showed that the follicles were lined by follicular cells of variable shaped nuclei. One has irregular nucleus with peripheral condensation of heterochromatin while, other cell has rounded nucleus. Intracytoplasmic electron lucent vacuoles were more prominent. In addition to that large fibroblast with large amount of collagen
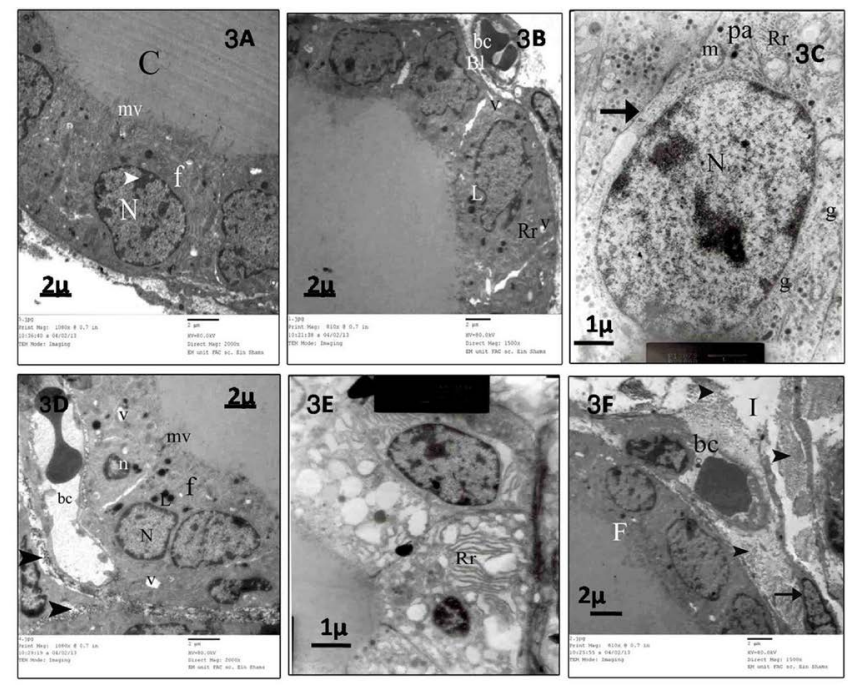

Figure 3: Ultrathin sections of control group(I) 3 A,B,C :3A: showing part of follicle lined by cuboidal cells $(f)$ that have rounded euchromatic nuclei ( $N$ (with clumps of heterochromatin (arrowhead). Their apical border shows microvill (mv) projecting into the colloid (C). 3B: follicular cell cytoplasm shows dilated cisternae of rough endoplasmic reticulum (Rr), a few vacuoles (v) and also dense lysosomal granules $(L)$.Note: blood capillary $(b c)$ beneath the thin basal lamina $(\mathrm{BI})($ Scale bar=2 $\mu \mathrm{m})$. 3C: showing parafollicular $(\mathrm{pa})$ with a rounded euchromatic nucleus $(\mathrm{N})$ lying on the basal lamina (arrow). Its cytoplasm contains many small electron-dense secretory granules $(\mathrm{g})$, mitochondria $(\mathrm{m})$ and also a few tubular cisternae of endoplasmic reticulum $(\mathrm{Rr})$ (Scale bar $=1 \mu \mathrm{m})$ 3D, E, F: EMF-exposed group (II) 3D: showing high cuboidal follicular cells (f). These cells have rounded nuclei $(\mathrm{N})$ with clumping of their peripheral heterochromatin. Dense lysosomal granule $(\mathrm{L})$ and numerous vacuoles $(\mathrm{V})$ are also seen. Their apical borders show microvilli $(\mathrm{mv})$. Other follicular cells have electron dense shrunken nuclei ( $n$ ). Dilated congested blood capillary (bc) and collagen fibers in interfollicular space (Scale bar= $2 \mu \mathrm{m})$. 3E: showing Numerous dilated irregular cisternae of rough endoplasmic reticulum $(\mathrm{Rr})$ with loss of their lamellar arrangement(Scale bar=1 $1 \mu \mathrm{m}) .3 \mathrm{~F}$ : demonsterate part of thyroid follicles $(\mathrm{F})$ and interstitium (I)containing congested blood capillary (bc). Notice large amount of collagen fibers (arrow head) and fibroblast (arrow) (Scale bar=2 $\mu \mathrm{m}$ ).
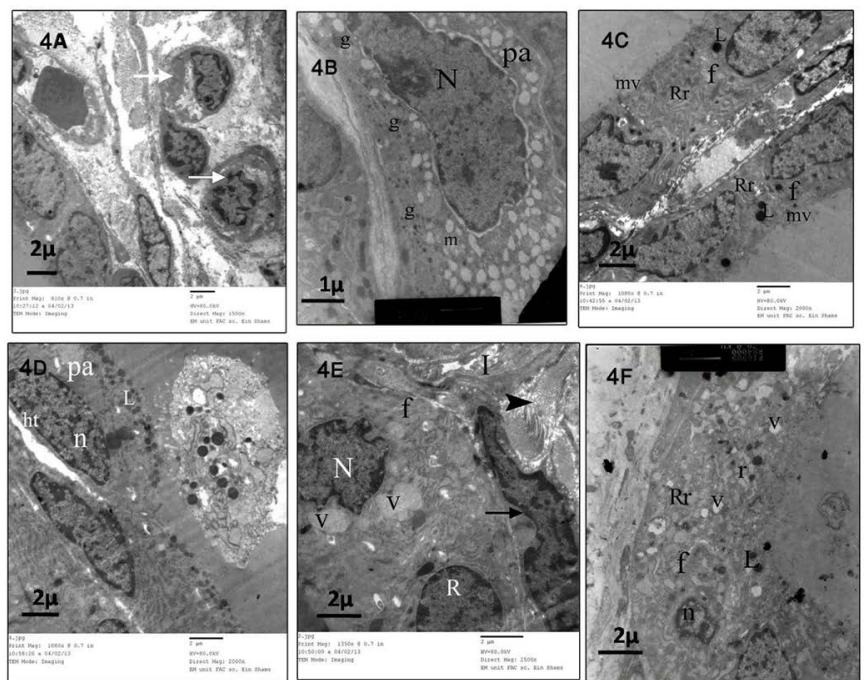

Figure 4: EMF-exposed group (II) 4A, B: A: showing Irregular nuclei of different cells (white arrow) (Scale bar=2 $\mu \mathrm{m}$ ). 4B: showing parafollicular cell (pa) lying on basement membrane. It has oval nucleus $(N)$, electron dense granules $(\mathrm{g})$ and abnormal mitochondria $(\mathrm{m})($ Scale bar $=1 \mu \mathrm{m})$. Vitamin E-treated group (III) 4C,D: C: showing different follicular cells (f); with numerous dilated cisternae of rough endoplasmic reticulum (Rr) and polymorphic dense lysosomal granules $(\mathrm{L})$. Their apical borders show microvilli (mv).4D: showing parafollicular cell $(\mathrm{pa})$ with inrdented nucleus $(\mathrm{n})$ and peripheral condensation of heterochromatin (ht).Its cytoplasm contains lysosomes $(L)$ with few electron dense granules $(\mathrm{g})($ Scale bar= $2 \mu \mathrm{m}) .4 \mathrm{E}$, F: recovery group (IV) 4E: showing (a) part of follicle lined by follicular cells ( $f$ ) of variable shaped nuclei. One has irregular nucleus $(\mathrm{N})$ with peripheral condensation of heterochromatin while, other cell has rounded nucleus $(R)$. Large intracytoplasmic electron lucent vacuoles $(v)$ are seen. Fibroblast (arrow) with large amount of collagen fibers (arrow head (is observed in interfollicular space (I). 4F: One follicular cell (f) has electron dense shrunken nucleus $(n)$.Its cytoplasm contains disorganized dilated RER (Rr), lysosomes $(\mathrm{L})$ and variable sized vacuoles $(\mathrm{V})($ Scale bar $=2 \mu \mathrm{m})$.

\begin{tabular}{|l|c|c|c|c|}
\hline Mean \pm SD & Control group & EMF exposed group & EMF-vitamin E & Recovery \\
\hline T3 ng/dL & $54.001 \pm 2.29$ & $38.574 \pm 2.14$ & $50.007 \pm 4.79$ & $40.754 \pm 2.10$ \\
\hline T4 ng/dL & $66.021 \pm 1.32$ & $50.592 \pm 1.46$ & $60.431 \pm 3.61$ & $51.582 \pm 1.46$ \\
\hline TSH microU/dL & $33.96 \pm 1.86$ & $43.16 \pm 1.46$ & $34.01 \pm 3.2$ & $40.16 \pm 1.4$ \\
\hline
\end{tabular}

The differences are significant at $p<.05$ highly significant $p<0.001$, compared to Group 1 (control)

Table 1: Shows relatively significant difference in T3, T4 and TSH levels in comparison to exposed and control groups

fibers were seen in interfollicular spaces (Figure 4E). Some follicular cells have electron dense shrunken nuclei and disorganized dilated RER. It contained lysosomes and variable sized vacuoles (Figure $4 \mathrm{~F}$ ).

\section{Biochemical results}

EMF exposed rats showed a significant decrease in serum T4 and a highly significant decrease in serum T3, as compared with the controls. However, there was a highly significant increase in serum TSH in the same group.

In vitamin $\mathrm{E}$ and recovery groups, there were regressions in these results as these groups showed relatively significant difference in T3, T4 and TSH levels in comparison to exposed and control groups (Table 1 and Figure 5).

\section{Morphometrical results}

In exposed group, the epithelial height was significantly decreased while; the collagen fiber content was significantly increased in comparison to control group. 


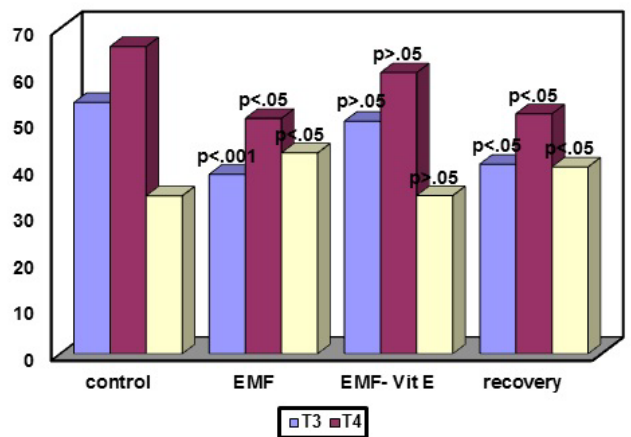

Figure 5: Shows relatively significant difference in T3, T4 and TSH levels in comparison to exposed and control groups

\begin{tabular}{|l|c|c|c|c|}
\hline Mean \pm SD & Control & EMF exposed & $\begin{array}{c}\text { EMF-Vitamin E } \\
\text { treated }\end{array}$ & Recovery \\
\hline Epithelial height & $9.05 \pm 0.83$ & $6.577 \pm 0.9^{*}$ & $8.306 \pm 0.83^{*}$ & $7.577 \pm 0.9^{*}$ \\
\hline $\begin{array}{c}\text { Connective } \\
\text { tissue area \% }\end{array}$ & $1.365 \pm 1.24 \#$ & $4.727 \pm 0.43^{*}$ & $1.534 \pm 0.19$ & $\begin{array}{c}3.632 \pm \\
0.40^{*}\end{array}$ \\
\hline
\end{tabular}

Marked differences * are significant at $p<.05$ compared to Group 1 (control)

Table 2: Shows marked increase in epithelial height in follicles as compared to the other two groups.

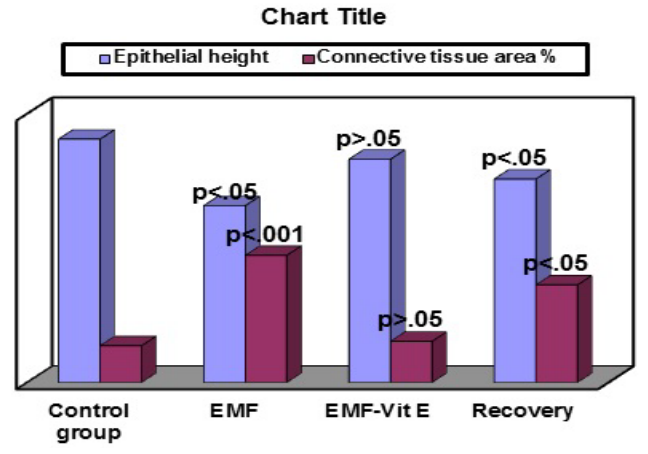

Figure 6: Shows marked increase in epithelial height in follicles as compared to the other two groups.

However, in vitamin E- treated group, there was marked increase in epithelial height in follicles as compared to the other two groups (II, IV). Additionally, The Collagen content in this group appeared more or less similar to the control group (Table 2 and Figure 6).

\section{Discussion}

Over the past few years, considerable attention has been given to the potential bio-effects of electromagnetic field (EMF) because it is a common constituent of many fields in our environments. Some lifestyles and occupations are associated with more than the average amount of exposure to electromagnetic fields [19].

As a consequence, the possible effects of EMF on biological systems were broadly investigated to offer optimistic data for a correlation between exposure to EMF and increased incidence of health hazards [20].

In the last few decades, various and intense investigations have been carried out in order to explore the possible biological effects of electromagnetic fields (EMF) on many human systems. Among several investigated systems; the endocrine gland has drawn the most considerable attention especially the pineal gland [21].
However, little knowledge about its effect on both histological and functional structure of thyroid gland is available. So, this study was designed to study both alterations and their reversibility.

The biochemical assay of rats exposed to EMF (Group II) showed significant $(p<0.05)$ and highly significant decrease $(p<0.001)$ in the level of serum T3 and T4, respectively in comparison to control rats. These results could be attributed to irradiation or blood protein degeneration $[22,23]$. Other possible reason for low T3 and T4 levels is the impaired exocytotic and endocytotic processes [24].

On the other hand, the level of TSH of same rats showed a highly significant increase $(\mathrm{p}<0.001)$ as compared with control rats. This finding might result from acute effects of radiation. Serum levels of T3, T4, and TSH were generally used as reliable indicators of the thyroid function in both humans and experimental animals. All reactions necessary for the formation of T3 and T4 are influenced and controlled by TSH level [25]. The elevation in TSH levels following irradiation could be explained by stimulation of the hypophysis [26] and/or tissue heating induced by EMF [6]. Moreover, exposure to EMF might influence the iodine uptake in the thyroid gland, and also prejudiced by increased temperature effect on pituitary gland [27].

However, Larsen et al. and Sert et al. [28,29] suggested that elevated serum level of TSH occurred due to active feedback mechanism. When the serum levels of T3 and T4 were decreased due to the radiation effects on the thyroid gland, the anterior pituitary gland released more TSH in the serum to stimulate the thyroid gland to produce more T3 and $\mathrm{T} 4$.

In the present work, alterations in thyroid gland function in the exposed group were further confirmed by the histological examination of the thyroid follicles which showed apparent light microscopic and ultrastructural changes. Many of these follicles underwent disintegration and disorganization. Some follicles appeared involuted and the others had interrupted follicular wall. The follicular cells had vacuolated cytoplasm and others had shedding of their epithelial lining in the lumina. Additionally, some follicular cells had darkly stained nuclei and cellular infilteration in interfollicular septa. The histological alterations of thyroid follicles could be explained by deficiency of stimulatory effects of TSH on the gland and hypoactivity [1]. The alterations in epithelial height were confirmed by morphometrical results.

It is well known that TSH is main factor influences structure and function of thyroid gland. Its simulative effect on the thyroid follicular cell is modulated by the action of a variety of molecules such as neuropeptides, peptides that derived from parafollicular cells and growth factors $[15,30]$.

Ultrastructurally, the glands of exposed rats showed that some follicles were lined by high cuboidal cells with clumping of peripheral heterochromatin. Their cytoplasm contained several vacuoles and electron dense lysosomes. Dilated cisternae of RER contained amorphous electron-lucent contents and lost their lamellar arrangement were also observed. Their apical border s showed a huge number of aggregated microvilli. In some cells, nuclei appeared often irregular in shape, shrunken with condensed heterochromatin. Parafollicular cells had abnormal mitochondria with ruptured cristea and few granules. These results accepted and explaind by some researcher Somozy [31]. It was reported that the cellular responses to different form of radiation or exposure to electromagnetic fields is manifested as irreversible and reversible structural and functional changes to cells and their organelles. Moreover, beside the morphological signs related to cell death, there are numerous reversible alterations in the structure of different cellular 
organelles. The radiation-induced changes in the supramolecular organization of membranes, including plasma membrane and membranes of different cell organelle those play a significant role in the development of acute radiation injury [16].

The biological effects of EMF remain a matter of debate; some reporters Wolf et al. [20] suggested that ELF-EMF induce free radical production through oxidative stress. On the other hand, LF-EMF could be induced lipid peroxidation that leads to alteration of the protein/ lipid ratio within the cell or its membrane. This peroxidation causes distraction of thiol groups existing in cell membrane and produce initiation of reactions leading to cell death [32-34].

Congested blood vessels and cellular infiltration were seen in thickened C.T septa that contained increased collagen fibers as morphometrically confirmed. These findings were recorded in other researches Rajkovic [15]. These changes explained by the direct effect of radiation $[35,36]$. On the other hand the shedding of epithelium lining of some follicles explained by indirect mechanisms of this vascular damage [37]. The perivascular lymphocytic infiltration could be attributed to immune-mediated reaction [38]. Also, Cutuli et al. [39] reported that increase lymphocytes after irradiation may act as defense mechanism against the effect of radiation and help in removal of apoptotic bodies.

Congestion observed in the vasculature of the thyroid gland was in agreement with Jubb et al. [40] who attributed it to the excess demand for blood to nourish the follicular cells. Moreover, Burton and Foster [41] explained these vascular changes by the effect of free radicals production and lipid peroxidation induced by radiation.

Also, the vascular effect of EMF might be exerted by the action of mediators released from mast cells that located around blood vessels and/or nerve fibers. These mediators are known to increase the thyroid blood flow, and additionally increase the capillary permeability [42]. Theoretically, the exposure to EMF enable the enhancement of blood flow through capillaries and concomitantly facilitate different molecules, such as TSH, to be driven to the thyroid by the bloodstream [15].

Some investigators Jereczek -Fossa et al. [43] and Madanat et al. [44] concluded that the reduction in blood level of thyroid hormone leads to activation of anterior pituitary to secrete more TSH to avoid the occurrence of hypothyroidism.

In the current work, examination of group III that received vitamin E during EMF exposure showed marked improvement in the histological structure of the gland as well as its biochemical parameters. Some thyroid follicles restored the appearance of controlled follicles. They were lined by cuboidal cells that had rounded nuclei. Other follicles were distended with colloid and lined by flattened cells. The peripheral vacuolation of colloid was returned indicating increase the activity of the gland. Minimal collagen fibers were seen in interfollicular connective tissue septa.

Vitamin E improves the biochemical and histological picture of thyroid gland. Combined EMF- exposed-vitamin E treated group showed variable sized follicles nearly similar to control with considerable improvement. El-Habit et al. [45] attributed this improvement to the radioprotective effect of vitamin E. Some reports [46] referred the radioprotective ability of antioxidant compounds to their ability to scavenge free radicals and/or their inhibition. Moreover, it was mentioned that vitamin $\mathrm{E}$ had the ability to intensify the proliferative activity of survived stem cells for replacement of the lost cells and the migration of viable cells from areas adjacent to the affected area to site of injured cells [47].
However, the partial recovery detected may be due to the short time left for the cell to regenerate. This had been demonstrated by Green et al. [48] who reported regeneration of follicular cells immediately and may be more effective with Vit.E for two weeks after exposure.

The levels of ROS in mammals are partially controlled by endogenous antioxidants; mainly glutathione (GSH) [49,50]. GSH concentrations in the plasma and tissue are inversely related to the level of oxidative stress [51]. A suppression of tissue GSH signifies that ROS and oxidative stress are increasing and the tissues became unprotected against the oxidative stress [26].

Some studies on mice liver had shown that exposure to EMF had a marked oxidant effect, suggesting that ROS were generated during the exposure period and may be a sign of the pathophysiological process of the EMF exposure. So, it is concluded that vitamin E could be improved the exposed rats by compensating the defect in endogenous antioxidant defense system [4].

In animals of recovery evaluation of thyroid gland, the secretory activity of their glands was preserved. The apparantly normal follicles were lined by flattened or low cuboidal epithelium and contained vacuolated colloid in their lumina. There were still some distorted and involuted follicles. Some disorganized follicles were devoid of colloid. The connective tissue components around the follicles appeared more prominent than in vitamin E-treated group and contained dilated blood vessels and moderate amount of collagen fibers. However, few follicles had darkly stained nuclei and cellular infilteration was also observed in wide intefollicular spaces. This morphological recovery cannot be supported with the physiological status of exposed animal because the decreased concentrations of $\mathrm{T} 3$ and $\mathrm{T} 4$ observed from the beginning to the end of the investigated recovery period. It is well known that TSH stimulates thyroglobulin exocytosis, endocytosis and proteolysis of the colloid droplets under normal physiological conditions. Additionally, TSH causes cytoskeletal protein phosphorylation and it is essential for pseudopod formation that leads to colloid endocytosis and, ultimately, thyroid hormone release [24]. So, The promising reasons, for low T3 and T4 levels after recovery period, might be the impaired processes of exocytosis and endocytosis at the apical membranes of follicular cells [12].

Some experimental investigations established the EMF effect on enzymes [52] and EMF-induced alterations in the structure and function of cellular membranes $[53,54]$ which considered as primary targets of EMF action in biological systems [55,56]. Serum T4 and T3 remained at considerably lower concentrations to the end of the recovery period. This record indicates that a longer period of time is required for the re-establishment of thyroid physiological homeostasis after EMF exposure.

The current work revealed histological changes in parafollicular (C) cell that evident at the ultrastructural level. This cell showed abnormal mitochondria with ruptured cristea and few granules in exposed group. While in vitamin E-treated group, C-cell had nearly normal appearance. In recovery group, the cell had indented nucleus and peripheral condensation of heterochromatin, few electron dense granules and lysosomes. These observations indicate the possibility of a relationship between the functional state of the thyroid gland and the activity of $C$ cells. It was suggested that the possible mechanisms involved in the changes in $\mathrm{C}$ cell with the thyroid status were in line with the alterations in the follicular cells. Considering that; the TSH level is increased in rats with hypofunctioning thyroid, three possible explanations (a) TSH mdirectly regulates C cells, (b) follicular cells regulate the $\mathrm{C}$ cells, and (c) $\mathrm{C}$ cells regulate follicular cells. However; the first hypothesis is supported by different reports $[57,58]$. 
Citation: Mohamed DA, Elnegris HM (2015) Histological Study of Thyroid Gland after Experimental Exposure to Low Frequency Electromagnetic Fields in Adult Male Albino Rat and Possible Protective Role of Vitamin E. J Cytol Histol 6: 374. doi:10.4172/2157-7099.1000374

In conclusion, the thyroid gland is sensitive to EMF exposure. This exposure induced morphological changes with drop off in serum $\mathrm{T} 4$ and T3. These changes remained to the end of the experiment indicating that a longer period of time is required for the return of normal thyroid activity after EMF exposure. Also, the results revealed considerable improvement by administration of vitamin $\mathrm{E}$ during the exposure period. Therefore, vitamin $\mathrm{E}$ is considered as a therapeutic hope for those exposed to EMF. Further studies are recommended using combination of vitamin $\mathrm{E}$ and other antioxidants either before or for long duration after EMF exposure.

\section{References}

1. Rajkovic V, Matavulj M, Lazetic B (2003) Extremely low frequency electromagnetic field influence on rat body mass. Annals of the Facualty of Engineering Hunedoara. Tome I, Fascicole 3: 5-10.

2. Strasák L, Vetterl V, Smarda J (2002) Effects of low-frequency magnetic fields on bacteria Escherichia coli. Bioelectrochemistry 55: 161-164.

3. Sabo J, Mirossay L, Horovcak L, Sarissky M, Mirossay A, et al. (2002) Effects of static magnetic field on human leukemic cell line HL-60. Bioelectrochemistry 56: $227-231$

4. Xu S, Okano H, Ohkubo C (2001) Acute effects of whole-body exposure to static magnetic fields and $50-\mathrm{Hz}$ electromagnetic fields on muscle microcirculation in anesthetized mice. Bioelectrochemistry 53: 127-135.

5. Sobczak A, Kula B, Danch A (2002) Effects of EMF on free-radical processes in steelworkers. Part II: Magnetic Field Influence on Vitamin A, E and Selenium Concentrations in Plasma. J Occup Health 44: 230-233.

6. Koyu A, Cesur G, Ozguner F, Akdogan M, Mollaoglu H, et al. (2005) Effects of $900 \mathrm{MHz}$ electromagnetic field on TSH and thyroid hormones in rats. Toxicol Lett 157: 257-262.

7. Zare S, Alivandi S, Ebadi AC (2007) Histological studies of the low frequency electromagnetic fields effect on liver, testes and kidney in guinea pig. World Appl Sci J 2: 509-511.

8. Ahlbom A (2001) Neurodegenerative diseases, suicide and depressive symptoms in relation to EMF. Bioelectromagnetics Suppl 5: S132-143.

9. IARC Working Group on the Evaluation of Carcinogenic Risks to Humans (2002) Non-ionizing radiation, Part 1: static and extremely low-frequency (ELF) electric and magnetic fields. IARC Monogr Eval Carcinog Risks Hum 80: 1-395.

10. Picazo ML, Migvel MP, Leyton V, Franco P, Varela L, et al. (1995) Long term effects of ELF magnetic fields on the mouse testis and serum testosterone levels. Electro-magnetobiol 14: 127-134.

11. Szemerszky R, Zelena D, Barna I, Bárdos G (2010) Stress-related endocrinological and psychopathological effects of short- and long-term $50 \mathrm{~Hz}$ electromagnetic field exposure in rats. Brain Res Bull 81: 92-99.

12. Mortavazi S, Habib A, Ganj-Karami A, Samimi-Doost R, Pour-Abedi A, et al. (2009) Alterations in TSH and Thyroid Hormones following Mobile Phone Use. Oman Med J 24: 274-278.

13. Balcer K, Elizabeth $\mathrm{K}$ (1995) Gene expression flowing $60 \mathrm{~Hz}$ magnetic field exposure. Environmental Health Perspectives, Boston MA, USA.

14. Institute of Laboratory Animal Resources (1996) Guide for the Care and Use of Laboratory Animals, National Academy Press, Washington, DC, USA.

15. Rajkovic V, Matavulj M, Johansson O (2006) Light and electron microscopic study of the thyroid gland in rats exposed to power-frquency electromagnetic fields. J Exp Biol 209: 3322-3328.

16. Matavulj M, Rajkovic V, Vscebrka G, Lukac T, Stevanovic D, et al. (2000) Studies on the possible endocrinological effects of an $50 \mathrm{~Hz}$ electromagnetic field. Centr Europ J Occup Environ Med 6: 183-188.

17. Bancroft JD, Gamble M (2002) Theory and Practice of Histological Techniques (5thedn), Churchill Livingstone. New York, London, Philadelphia, USA

18. Glauert AM, Lewis PR (1998) Biological Specimen Preparation for Transmission Electron Microscopy. Vol. 17, Portland press, London.

19. Sedghi H, Zare S, Hayatgeibi H, Alivandi S, Ebadi A (2005) Effect of $50 \mathrm{HZ}$ magnetic field on some factors of immune system in the male guinea pigs. American J Immunology 1: 37- 41
20. Wolf FI, Torsello A, Tedesco B, Silvia F, Boninsegma A, et al. (2005) 50-Hz extremely low frequency electromagnetic fields enhance cell proliferation and DNAdamage: Possible involvement of a redox mechanism. Biochimia Biophysica Acta 1743: 120-129.

21. Graham C, Cook MR, Sastre A, Gerkovich M, Kavet R (2000) Cardiac autonomic control mechanisms in power-frequency magnetic fields: a multistudy analysis. Environ Health Perspect 108: 737-742.

22. Nadol'nik LI, Netsetskaia ZV, Vinogradov VV (2003) Effects of single-dose external gamma irradiation on rat thyroid status as observed during the year. Radiats Biol Radioecol 43: 65-70.

23. Nadol'nik LI, Netsetskaia ZV, Kardash NA, Martynchik DI, Kravchuk RI, et al (2004) Functional and morphological characterization of rat thyroid gland at remote periods following single high and low dose radiation exposure. Radiats Biol Radioecol 44: 535-543.

24. McNabb A (1992) TSH effects on the thyroid. Prentice Hall, New Jersey, pp. 56-69.

25. Kelly GS (2000) Peripheral metabolism of thyroid hormones: a review. Altern Med Rev 5: 306-333.

26. Hashish A, El-Missiry M, Abdelkader H, Abou-Saleh R (2008) Assessment of biological changes of continuous whole body exposure to static magnetic field and extremely low frequency electromagnetic fields in mice. Ecotoxicol Environ Saf 71: 895-902.

27. Turker $H$ (2004) Effect of ultraviolet radiation on total plasma T3, total plasma T4 and TSH hormones in Molerat (Spalax leucodon) GU Fen Bilimleri Dergisi 17: 1-8.

28. Larsen PR, Terry FD, lan DH (1998) The thyroid gland. In: Wilson JD, Williams text book of Endocrinology, (9thedn), Saunders company, Philadelphia, USA.

29. Sert C, Celik MS, Akdag Z, Ketani MA, Nergiz V (2000) The radioprotective effect of vitamins $C, E$ and vitamin $E+$ Glutathione on the small intestine and the thyroid gland in rats irradiated with $X$ rays. Turk J Mod Sci 30: 417-425.

30. Ahrén B (1991) Regulatory peptides in the thyroid gland--a review on their localization and function. Acta Endocrinol (Copenh) 124: 225-232.

31. Somosy Z (2000) Radiation response of cell organelles. Micron 31: 165-181.

32. Gutteridge JM, Halliwell B (1990) The measurement and mechanism of lipid peroxidation in biological systems. Trends Biochem Sci 15: 129-135.

33. Halliwell B, Chirico S (1993) Lipid peroxidation: its mechanism, measurement and significance. Am J Clin Nutr 57: 715S-724S.

34. Schaich KM (1992) Metals and lipid oxidation. Contemporary issues. Lipids 27: 209-218.

35. Delaney JP, Bonsack ME, Felemovicius I (1994) Radioprotection of the rat small intestine with topical WR-2721. Cancer 74: 2379-2384.

36. Cannon CR (1994) Hypothyroidism in head and neck cancer patients: experimental and clinical observations. Laryngoscope 104: 1-21.

37. Bogdanova TI, Zurnadzhy LY, Greenebaum E, McConnell RJ, Robbins J, et al. (2007) A Cohort study of thyroid cancer and other thyroid diseases after the Chernobyl accident: pathology analysis of thyroid cancer cases in ukraine detected during the first screening (1998-2000). Cancer 107: 2559-2566.

38. Hancock SL, McDougall IR, Constine LS (1995) Thyroid abnormalities after therapeutic external radiation. Int J Radiat Oncol Biol Phys 31: 1165-1170.

39. Cutuli B, Quentin P, Rodier JF, Barakat P, Grob JC (2000) Severe hypothyroidism after chemotherapy and locoregional irradiation for breast cancer. Radiother Oncol 57: 103-105

40. Jubb KV, Kennedy PO, Palmer N (1985) Pathology of domestic animals. (3rd edn). Academic press, San Diego. pp: 266-280.

41. Burton G, Foster DO (1995) Biological antioxidant. Phiolos Trans Soc Lend Brol Sci 331: 565-578.

42. Michalkiewicz M, Huffman LJ, Dey M, Hedge GA (1993) Endogenous neuropeptide $Y$ regulates thyroid blood flow. Am J Physiol 264: E699-705.

43. Jereczek-Fossa BA, Alterio D, Jassem J, Gibelli B, Tradati N, et al. (2004) Radiotherapy-induced thyroid disorders. Cancer Treat Rev 30: 369-384.

44. Madanat Laura-Maria S, Lähteenmäki PM, Alin J, Salmi TT (2007) The natura history of thyroid function abnormalities after treatment for childhood cancer Eur J Cancer 43: 1161-1170. 
Citation: Mohamed DA, Elnegris HM (2015) Histological Study of Thyroid Gland after Experimental Exposure to Low Frequency Electromagnetic Fields in Adult Male Albino Rat and Possible Protective Role of Vitamin E. J Cytol Histol 6: 374. doi:10.4172/2157-7099.1000374

Page 8 of 8

45. El-Habit OH, Saada HN, Azab KS, Abdel-Rahman M, El-Malah DF (2000) The modifying effect of beta-carotene on gamma radiation-induced elevation of oxidative reactions and genotoxicity in male rats. Mutat Res 466: 179-186.

46. Kumar SS, Chaubey RC, Devasagayam TP, Priyadarsini KI, Chauhan PS (1999) Inhibition of radiation-induced DNA damage in plasmid pBR322 by chlorophyllin and possible mechanism(s) of action. Mutat Res 425: 71-79.

47. Cherdyntseva N, Shishkina A, Butorin I, Murase H, Gervas P, et al. (2005) Effect of tocopherol- monoglucoside (TMG), a water-soluble glycosylated derivate of vitamin $\mathrm{E}$, on hematopoietic recovery in irradiated mice. J Radiat Res 46: $37-41$

48. Green LM, Patel Z, Murray DK, Rightnar S, Burell CG, et al. (2002) Cytoskeleta and functional changes in bioreactor assembled thyroid tissue organoids exposed to gamma radiation. J Radiat Res 43: 213-218.

49. Reiter RJ, Tan DX, Qi WB (1998) Suppression of oxygen toxicity by melatonin. Zhongguo Yao Li Xue Bao 19: 575-581.

50. Reiter RJ, Tan DX, Cabrera J, D'Arpa D, Sainz RM, et al. (1999) The oxidant/ antioxidant network: role of melatonin. Biol Signals Recept 8: 56-63.

51. Richie JP Jr (1992) The role of glutathione in aging and cancer. Exp Geronto 27: $615-626$.
52. Ding GR, Wake K, Taki M, Miyakoshi J (2001) Increase in hypoxanthineguanine phosphoribosyl transferase gene mutations by exposure to electric field. Life Sci 68: 1041-1046.

53. Lisi A, Pozzi D, Pasquali E, Rieti S, Girasole M, et al. (2000) Three dimensiona (3D) analysis of the morphological changes induced by $50 \mathrm{~Hz}$ magnetic field exposure on human lymphoblastoid cells (Raji). Bioelectromagnetics 21: 46-51.

54. Bordivshkov IN, Goroshinskaya IA, Frantsiyants EM, Tkacheva GN, Gorlo El et al (2000) Structural-functional changes in lymphocytes and erythrocytes membranes after exposure to alternating magnetic field. Vopr Med Khim 46: 72-80.

55. Tenforde TS, Kaune WT (1987) Interaction of extremely low frequency electric and magnetic fields with humans. Health Phys 53: 585-606.

56. Goodman EM, Greenebaum B, Marron MT (1995) Effects of electromagnetic fields on molecules and cells. Int Rev Cytol 158: 279-338.

57. Dadan J, Zbucki RL, Sawicki B, Winnicka MM, Puchalski Z (2003) Activity of the thyroid parafollicular $(C)$ cells in simple and hyperactive nodular goiter treated surgically-preliminary investigations. Folia Morphol (Warsz) 62: 443-445.

58. Martín-Lacave I, Borrero MJ, Utrilla JC, Fernández-Santos JM, de Miguel M, et al. (2009) C-cells evolve at the same rhythm as follicular cells when thyroidal status changes in rats. J Anat 214: 301-309. 